them verbally, then discusses them in a more conventional way in footnotes. He further enlivens the proceedings by linking the equations with the personalities and lives of the scientists after whom they are named. For instance, the Scholander bomb, a device used to measure pressure in stems, gets its name from the Scandinavian-born physiologist Per Scholander (1905-80), who was renowned for his ingenious experimental-apparatus designs. Vogel's approach certainly worked for me.

As for the jocularity, there is much that is quotable. I love the description of the superhydrophobicity of leaves as "particle pickup predilection", and the idea that ice is "toxic water" from a leaf's perspective. But some of the puns jar - the phrase "to a plant, our water loss problem would be a wet dream" struck me as condescending and crass.

Gags notwithstanding, Vogel does makes the conscientious reader work, although this is more of a challenge than a chore. His focus leaves some issues hanging - forcing us to dig further elsewhere. And he rightly notes that there is still a lot to discover. How, for example, do deciduous trees re-establish unbroken water columns through their trunks to the new leaves in spring?

He even urges readers to do their own demonstrations and experiments at home, to illustrate basic principles in a way that words never can. A loop of thread placed in a glass of water will not form a regular shape, but add a bit of detergent to reduce the surface tension and hey presto: a perfect circle (and party trick). And it is fun to whirl around in the garden holding a stick with leaves attached to the end - especially if you're demonstrating how the leaves behave in the 'wind' you create, which can easily reach 30 kilometres an hour.

The role of phylogeny - the evolutionary relationships between plants is completely left out of this book. Vogel is a proponent of the adaptationist programme, in which every feature has a function that serves the organism well. He pays lip service to an alternative view by referencing his late friend Stephen Jay Gould, but I think the role of chance in evolution deserves more than just a mention. Features of organisms do not always have a purpose. Sometimes they just are.

Probably the central theme of The Life of a Leaf is extracting the extraordinary from the ordinary. In a way, Vogel's view is that science is at its heart simple - and great fun. I couldn't agree more.

Sandra Knapp is a botanist at the Natural History Museum in London. e-mail:s.knapp@nhm.ac.uk

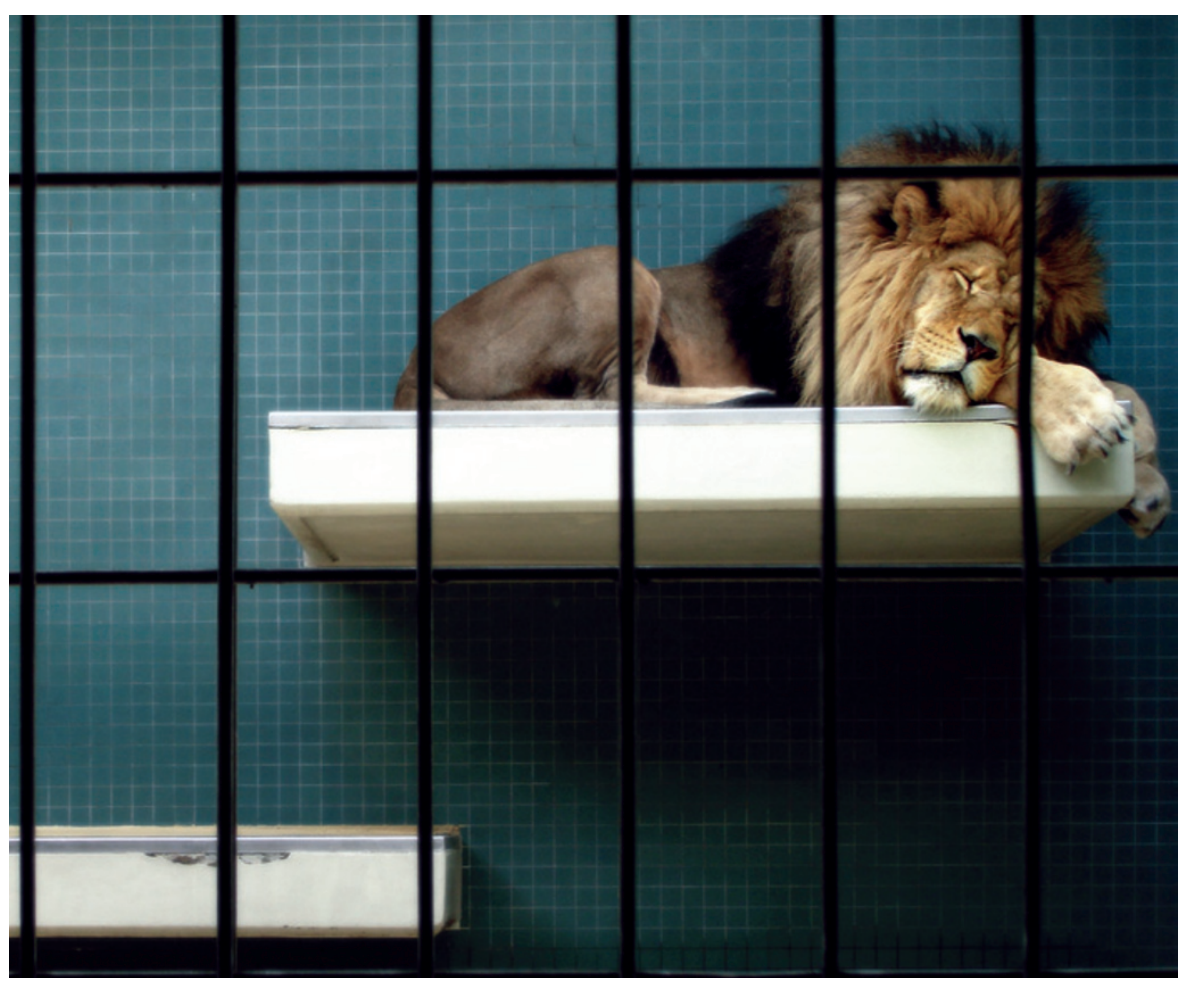

Life in a cage disconnects animals from the natural world and breeds apathy.

\title{
ZOOLOGY
}

\section{The animal inside}

\section{Josie Glausiusz contemplates a documentary on the human relationship with animals confined and stuffed.}

A lion lies asleep atop a glass roof inside a wire enclosure. Beneath the glass, within an enclosed walkway, tourists lift their smartphones and snap photos of the torpid feline. What do they see when they look at it - a magnificent beast, or a cowed one, disconnected from its natural world?

Questions about what we really see when we look at animals run throughout Bestiaire, a strange and unsettling documentary directed by Canadian Denis Côté. Awarded a Special Jury Prize at the 2012 Environmental Film Festival at Yale, held in New Haven, Connecticut, Bestiaire continually confounds the viewer, undermining our understanding of what it means to be wild, as it reflects our own confined lives.

The film unfolds over four seasons, shot mostly inside Parc Safari, a zoo in Hemmingford in Quebec, Canada. There is no narration and little dialogue, and disparate scenes seem to pop up at random. We move from art students sketching what looks like a stuffed baby deer to snow-filled pens in which woolly bison, llamas and horses lumber back and forth. Zebras stomp frantically. A melancholy monkey cuddles a stuffed teddy bear. In summer, geese waddle through tall grass and children take elephant rides and pat young deer.

People feature too. Guards watch and feed the animals through the mesh of the cages - and are themselves observed on closedcircuit cameras. At one point the film's focus shifts to a taxidermy studio in a Montreal basement, crammed with skulls and stuffed

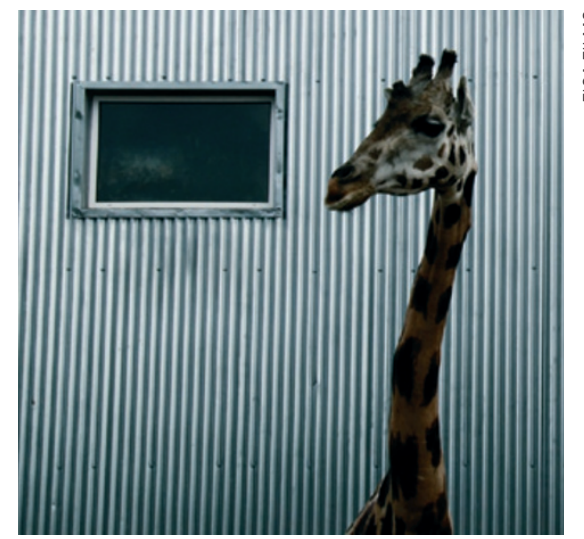

Bestiare raises unsettling questions about humanity's habit of gawking at confined animals. 
Bestiaire DIRECTED BY DENIS CÔTÉ FiGa Films: 2012

Screening at Anthology Film Archives in New York 19-25 October. deer heads. A man walks up to a rotating metal drum and removes what looks like a handful of dusty feathers. He shakes it, slices out bloody bones with surgical tools, stuffs it, dries it with a hair-dryer and voilà - a green-headed duck.

Although Côté insists that Bestiaire has no message, it nonetheless depicts perfectly the distorted relationship that zoo-goers and others have with wild animals: no longer free, but dispirited creatures that we incarcerate, ogle, coddle and capture on tiny screens.

That, in turn, raises compelling questions about the role of zoos today. Humans have enjoyed gawking at imprisoned animals since as long ago as $2100 \mathrm{BC}$, when Mesopotamian kings exhibited lions in cages and pits. The Tower of London was once home to a menagerie that over the centuries featured lions, tigers, alligators and hyenas, whose bodies were dissected in the pursuit of anatomical science. London Zoo took over from it in 1828. Now, an emerging consensus argues that zoos should discard the old 'entertainment' model to devote resources to the conservation of animals that face extinction in the wild. A coordinated zoo-breeding programme of the golden lion tamarin (Leontopithecus rosalia), for example, has helped the endangered monkey to thrive once again in its fragmented Brazilian forest habitat.

Life in a cage may protect an animal from habitat destruction, but it also breeds apathy. In one spring-time scene in Bestiaire, three bears line up obediently in a pen as a keeper tosses grapes into their open mouths. Denied the opportunity to forage far and wide, they seem to have adapted to a life free from independent exploration.

In an interview, Côté recalled that he wanted his film to be like seeing "through the eyes of a six-year-old who is turning the pages of a bestiary and excited to discover a new picture of an animal at every turn". But the medieval bestiary was also an instructional book, filled with illustrations of animals both real and imaginary - elephants and lions, griffins and unicorns - each of which had a symbolic moral or allegorical value. Like these didactic tomes, Côtés film shows us that we face ethical choices: understand and empathize with the plight of wild animals or treat them as yet more playthings to be photographed, toyed with or stuffed.

Bestiaire prompts viewers to ponder what it really means to be human - or more accurately, humane - in our relationships with wild beasts. Whether or not Côté intended it, the movie has a message - a powerful one. -

Josie Glausiusz is a writer based in New York City.

e-mail:josiegz@gmail.com

\section{Books in brief}

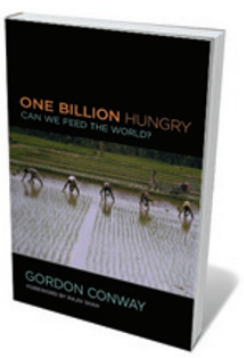

One Billion Hungry: Can We Feed the World?

Gordon Conway CORNELL UNIVERSITY PRESS 456 pp. £46.50 (2012)

Poverty, climate change, booming population, soaring food prices - the obstacles to global food security seem Himalayan. Agricultural ecologist Gordon Conway calls for a "doubly green revolution", with sustainable intensification of production, research and development, and market creation. He ploughs through the crises, discusses methods, delves into the role of farmers as innovators, and faces up to environmental challenges. An impressive marshalling of case studies, new research and long experience from an expert in the field.

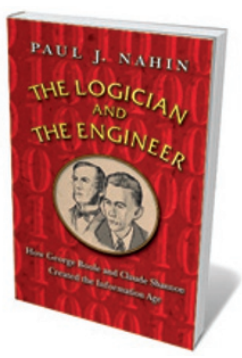

The Logician and the Engineer: How George Boole and Claude Shannon Created the Information Age

Paul J. Nahin PRINCETON UnIVERSITY PRESS 244 pp. £16.95 (2012) Meshing logic problems with the stories of two extraordinary men - Victorian philosopher-mathematician George Boole and twentiethcentury information theorist Claude Shannon - Paul Nahin fashions a tale of innovation and discovery. Boole's astonishingly advanced ideas seeded Boolean algebra, which underpins the electronic circuits governing today's digitized culture. Alongside a gripping account of how Shannon built on Boole's work, Nahin explores others key to the technological revolution, from Georg Cantor to Alan Turing.

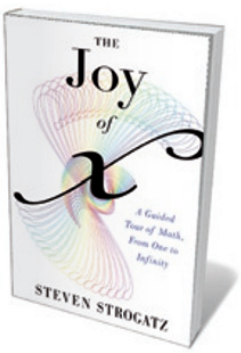

The Joy of X: A Guided Tour of Math, from One to Infinity Steven Strogatz HoUGHTON MIFFLIN HARCOURT 336 pages $£ 16.87$ (2012)

Is infinity a number? What is the point of quadratic equations? Whither topology? Steven Strogatz, a mathematician in the field of complex networks, steers the 'maths challenged' through his home territory. Beginning with the usefulness of numbers, Strogatz strolls through $\pi$, the Pythagorean theorem, probability, solid geometry and more, including the anatomy of that marvellous beast, calculus. The interconnectedness of maths in culture - from art, literature, philosophy and law to medicine - is gracefully unravelled.

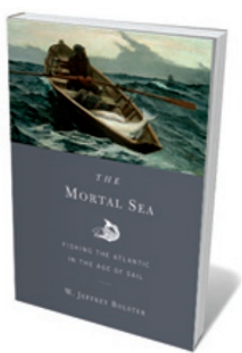

Mortal Sea: Fishing the Atlantic in the Age of Sail

W. Jeffrey Bolster HARVARD UNIVERSITY PRESS 366 pp. £22.95 (2012)

Historian and seafarer Jeffrey Bolster "writes the ocean into history", tracing the currents leading to today's serious fish-stock depletion. Focusing on the North Atlantic from Cape Cod to Newfoundland's Grand Banks, he shows how one species after another - halibut, lobster, cod - has been exploited for centuries, long before industrialization. Bolster braids marine biology into a narrative driven by courageous chancers, such as fifteenth-century explorer John Cabot and unnamed hordes of fishermen, to argue that the precautionary approach is key to heading off collapse.

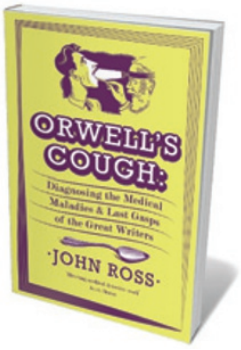

Orwell's Cough: Diagnosing the Medical Maladies and Last Gasps of the Great Writers

John Ross ONEWORLD PUBLICATIONS 288 pp. £12.95 (2012)

Shakespeare may have had syphilis and mercury-vapour poisoning, speculates medical doctor John Ross in this engrossing look at how great writers have grappled with illness and disease. From the satirist Jonathan Swift's putative descent into frontotemporal dementia to Herman Melville's bipolar disorder (and possible ankylosing spondylitis), a book that compels respect for the subjugation of suffering behind so many enduring works of genius. 